$\operatorname{cocos}$ (1994-1995), 10, 01 - 09

Printed in Sri Lanka

\title{
A COMPARISON OF TWO COCONUT CULTIVARS FOR HIGH PRODUCTIVITY UNDER IRRIGATION
}

\author{
R R A Peries \\ Coconut Research Institute, Lunuwila, Sri Lanka
}

\begin{abstract}
Over four decades of research indicate that the cultivar CRIC65 is capable of producing a sustained higher yield compared to CRIC60 in the absence of adverse soil water deficit. Data indicate that the cumulative yield of nuts and copra are $50 \%$ higher in CRIC65 than in CRIC60 over a period of 32 years. Inadequate soil water would appear to be the main limiting factor to the yield production in CRIC65. The argument is, therefore made, that if coconut is to be grown under irrigation, the cultivar CRIC65 should be selected due to its high potential productivity.

\section{INTRODUCTION}

The last decade in Sri Lanka has seen adverse changes in the rainfall pattern (CDA, 1990; D T Mathes, pers. comm.) affecting coconut. The frequent occurrence of prolonged rain-free periods in traditional coconut growing areas have caused a wide fluctuation in the national yield, ranging between 2000 and 3000 million nuts per year (CDA, 1990). Soil water conservation measures and growing putative. drought tolerant cultivars have yet to significantly alter this pattern of yield variation. While breeding cultivars which are drought tolerant is essentially a slow process, one method of overcoming the adversities of prolonged rain-free periods is the provision of supplementary irrigation for coconut. The Coconut Research Institute of Sri Lanka (CRISL), has developed a low-cost, gravity flow, drip irrigation system, appropriate for coconut land (Jayasekara, 1989). However, in view of the escalating costs of production, it is essential that a potentially high yielding coconut cultivar be introduced along with irrigation for increased productivity and ultimately profit. This paper discusses the merits and demerits of two improved cultivars (CRIC60 and CRIC65) introduced by the CRISL, with the objective of recommending to the grower the hybrid-CRIC65 which has a higher potential productivity under conditions of non-limiting soil water and nutrient supply.
\end{abstract}

\section{Data Evaluation}

Supplementary irrigation is intended to prevent the coconut palm from reaching critical levels of soil water deficit. It has been shown in the Ivory Coast that for every $100 \mathrm{~mm}$ of soil water deficit, the copra yield of adult coconut can be reduced by as much as $500 \mathrm{~kg} \mathrm{ha}^{-1} \mathrm{yr}^{-1}$ (Rognon and Delbosc, 1990.). The ordinary tall palm 
is known to use between 120 to $150 \mathrm{~mm}$ of soil water per month (Jayasekara et al., 1993). If the reserve of soil water and the rainfall during a particular period is inadequate to meet the evapotranspiration requirement of the palm, it will undergo water deficit and result in reduced productivity (Abeywardana, 1968; 1971). The supplementary irrigation will ensure the availability of an adequate quantity of soil water to the palm at all times.

Three main cultivars of coconut are currently popular amongst growers. in Sri Lanka, namely the ordinary tall, CRIC60 and the hybrid-CRIC65. The CRIC60 is superior to the ordinary tall in that both its parents have been selected for higher productivity and for their ability to transmit this character to their progenies to a large extent. In addition, a certain degree of drought tolerance has also been introduced into this cultivar over the years through natural selection.

The CRIC65 hybrid is a cross between the dwarf (kundira) and the tall and carries the early bearing habit of the dwarf in the hybrid ( 3 to 4 years) compared to the CRIC60 which takes approximately 6 to 7 years for uniform bearing under plantation conditions. However, the CRIC65 hybrid carries the drought susceptible character which is inherited from the dwarf, and which limits its cultivation to areas not.frequently prone to prolonged rain-free periods. The early growers who were fascinated by the precocity (early bearing) and the high productivity of the CRIC65, paid little or no attention at all to its limitations and cultivated this hybrid in low rainfall (dry) areas or in soils with a low soil water storage and availability. This led to many of the hybrid plantations failing as a result of adverse soil water deficit. However, when CRIC65 has been grown in "suitable" areas and when appropriate agronomic packages have been provided, the response has been excellent.

A comparison of some yield characters of the CRIC60 and CRIC65 under experimental conditions is made in Table 1. Information presented here gives an indication of the relative performance of these two improved cultivars, under different growing conditions.

Figure 1a. Shows the temporal pattern of yield (nuts palm ${ }^{-1}$ ) development in the two cultivars, in response to the agro-ecology in which they are grown. The adult CRIC65 plantation which was used in this study was planted in 1950 at Rathmalagara estate, Madampe and is currently 43 years of age. The plantation of CRIC60 (Field no. 1 of the Isolated Seed Garden at Amabakelle) is 38 years of age. While the total annual rainfall between the two sites have not varied much over the period under consideration, the gravelly (lateritic) soil at Ratmalagara is known for its low productivity of coconut compared to the sandy loam soils of the Isolated Seed Garden. The first year of bearing in both cultivars is taken as the fifth year after planting. Both cultivars have been raised under average conditions and received fertilizer at the standard recommended rates. Being improved cultivars, they did not receive additional fertilizer until the nutrient and productivity based fertilizer application was recommended in 1989 (Jayasekara, 1989). Figure 1b shows the total annual rainfall corresponding to each year of production (i.e. rainfall of the preceding year). The yield response to poor rainfall distribution can be noted here. 
Years in which a marked drop in yield was recorded by each cultivar are also indicated in Figure 1a. When there was poor rainfall distribution, the drop in yield for CRIC60 was higher compared to CRIC65. Conversely when there was good rainfall distribution, the increase in yield for CRIC65 was much higher.

Table 1. A comparison of some yield characters of CRIC60 and CRIC65 cultivars under experimental conditions.

\begin{tabular}{|c|c|c|}
\hline \multirow[b]{2}{*}{ Parameter } & \multicolumn{2}{|c|}{ Variety } \\
\hline & CRIC 60 & CRIC 65 \\
\hline 1. Bearing age & $5-7$ years & $3-4$ years \\
\hline $\begin{array}{l}\text { 2. Nuts/palm/year } \\
\text { (general experimental) }\end{array}$ & 110 & 120 \\
\hline 3. Copra/nut (g) & $200-225$ & $210-220$ \\
\hline $\begin{array}{l}\text { 4. Yield in 5th year nuts/paim } \\
\text { (Manthriratne, 1978) }\end{array}$ & 11 & 23 \\
\hline $\begin{array}{l}\text { 5. Yield in 8th year without water } \\
\text { deficit, (Peries, 1992) }\end{array}$ & $\begin{array}{l}26 \text { nuts palm } \\
\left.\text { (Copra: } 5.2 \mathrm{~kg} \mathrm{palm}^{-1}\right)\end{array}$ & (Copra: $9 \mathrm{~kg} \mathrm{palm}^{-1}$ ) \\
\hline $\begin{array}{l}\text { 6. Yield in 8th year with mild } \\
\text { water deficit (B/E)(Peries, 1992) }\end{array}$ & $\begin{array}{l}23 \text { nuts palm } \\
\left.\text { (Copra: } 4.3 \mathrm{~kg} \mathrm{palm}^{-1}\right)\end{array}$ & $\begin{array}{c}24 \\
(\text { Copra:4.3 kg palm })\end{array}$ \\
\hline $\begin{array}{l}\text { 7. Yield at } 7 \text { years } \\
\text { (Manthriratne, 1965) }\end{array}$ & & $\begin{array}{c}66 \\
\left.\text { (Copra: } 19 \mathrm{~kg} \mathrm{palm}^{-1}\right)\end{array}$ \\
\hline $\begin{array}{l}\text { 8. Yield at } 19 \text { years (R/E) } \\
\text { (Manthriratne, 1978) }\end{array}$ & 107 & 153 \\
\hline
\end{tabular}

R/E : Rathmalagara Estate

B/E: Bandirippuwa Estate

Figure 2 shows the cumulative yield of each cultivar from the first year of bearing up to the present time (end 1992). The cumulative yield for 32 years of bearing was $51 \%$ higher in the CRIC65 than in CRIC60. The same set of data in Figure 3 shows the four year moving average yield of the two cultivars. It is very clear that the CRIC65 hybrid has maintained an overall higher yield profile than the CRIC60, under changing weather (rainfall) patterns and in the absence of any supplementary irrigation. It is also apparent that the response to poor rainfall distribution has often been less severe in CRIC65 than in CRIC60, particularly in the latter years of production. The data presented here further bring to light the following important characteristics on the performance of these two cultivars. 
a. Five years from flowering, CRIC65 yielded 110 nuts palm ${ }^{-1} \mathrm{yr}^{-1}$, while CRIC60 had achieved only $50 \%$ of this. In terms of Copra this would be $22 \mathrm{~kg} \mathrm{palm}^{-1}$ from CRIC65 against $13.5 \mathrm{~kg} \mathrm{palm}^{-1}$ from CRIC60. This yield difference is also reflected in the cumulative yield over 32 years.

b. Twelve years after flowering, the CRIC65 hybrid had achieved its highest yield (depending on the potential of the environment) of nearly 200 nuts palm ${ }^{-1} \mathrm{yr}^{-1}$, whereas at this age the CRIC60 had only achieved a 125 nuts palm $^{-1} \mathrm{yr}^{-1}$.

c. After about the twelfth year, the four year moving average yield per paim showed a steady decline in CRIC65, and reached an average of about 110 nuts palm ${ }^{-1}$ $\mathrm{yr}^{-1}$. This would amount to about 17,000 nuts ha $\mathrm{hr}^{-1}$ (at 150 palms ha ${ }^{-1}$ ). The variations in yield over and above the four year moving average in the CRIC65 was due to the fluctuations in weather, mainly rainfall. If the soil water was non-limiting, maintaining a yield level of 150 nuts palm ${ }^{-1} \mathrm{yr}^{-1}$ from the CRIC65 hybrid would not have been an apparently difficult task, which would amount to over 20,000 nuts $^{-1}$ $\mathbf{y r}^{-1}$.

d. In the CRIC60, there was an apparent tendency for the yield profile to flatten-off between 12 and 32 years of bearing. This was associated with fluctuations in yield ranging between 20 and 110 nuts palm ${ }^{-1} y^{-1}$. These fluctuations were also indicated in the four year moving average yield after the tweltth year of bearing, where under conditions of favourable soil water supply, the palms yielded 110 nuts yr.'.

e. Thus, with an adequate amount of soil water and nutrients made available in the root zone, it could be said that CRIC 60 has the potential to yield an average of about 110 nuts palm ${ }^{-1} \mathrm{yr}^{-1}$, while the CRIC65 would yield around 150 nuts palm $\mathrm{yr}^{-1}$ or more.

\section{DISCUSSION AND CONCLUSION}

The CRIC65 seedlings currently issued to the growers, are produced from a population of $d w a r f$ palms at ISG, which are emasculated and allowed to pollinate freely with pollen from an elite set of tall palms. Within the population of both dwarfs and talls; there has been little deliberate selection for any desirable traits in the production of the $d$ warf $\times$ tall (CRIC65) hybrids. It has been observed in recent experiments (Peries and Jayasekera unpublished data) that in deep latosols these hybrids are able to extract water below a depth of $3 \mathrm{~m}$, due to the production of a deep root system. In shallow or hard (gravelly) soils the productivity of CRIC65 has therefore to be limited by the non availability of water during critical periods of yield development due to the physical impediment to root growth. If roots are able to reach the water table, then the productivity of the palm cannot be affected to a considerable extent by any other environmental factor, provided, adequate amounts of nutrients are available to the plant. From the CRIC60 and CRIC65 cultivars grown in a fully randomized trial in a 'dry' area (see Table 1, Peries, 1992) under rainfed conditions, it was clear that when roots accessed deep water and palms were not affected by water deficit, the productivity was higher in CRIC65 than CRIC60. 

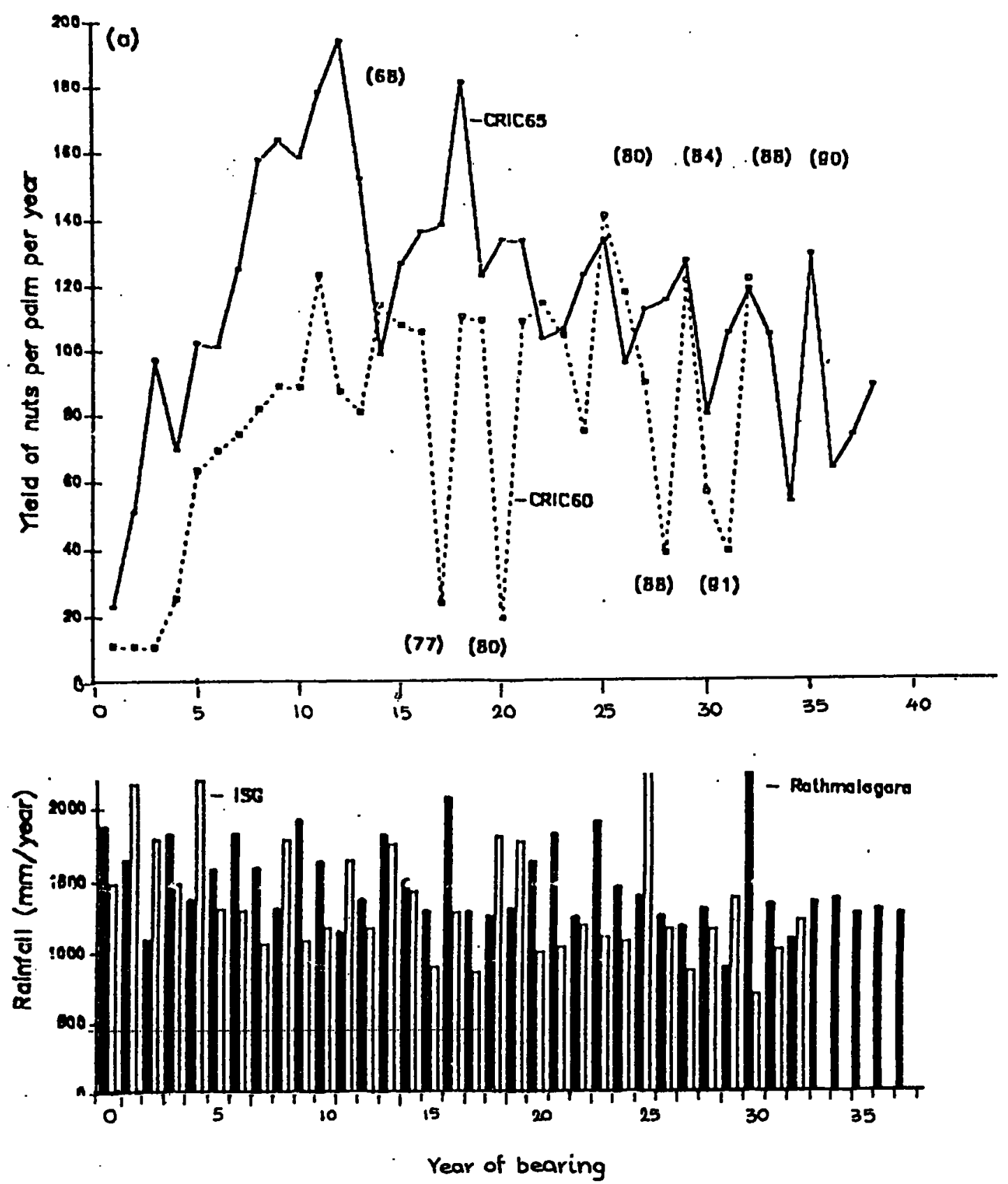

Figure 1 (a) The temporal pattern of yield variation in CRIC60 and CRIC65 in response to changes in rainfall pattern.

(b) The rainfall at ISG and RE, corresponding to the different years of production. 


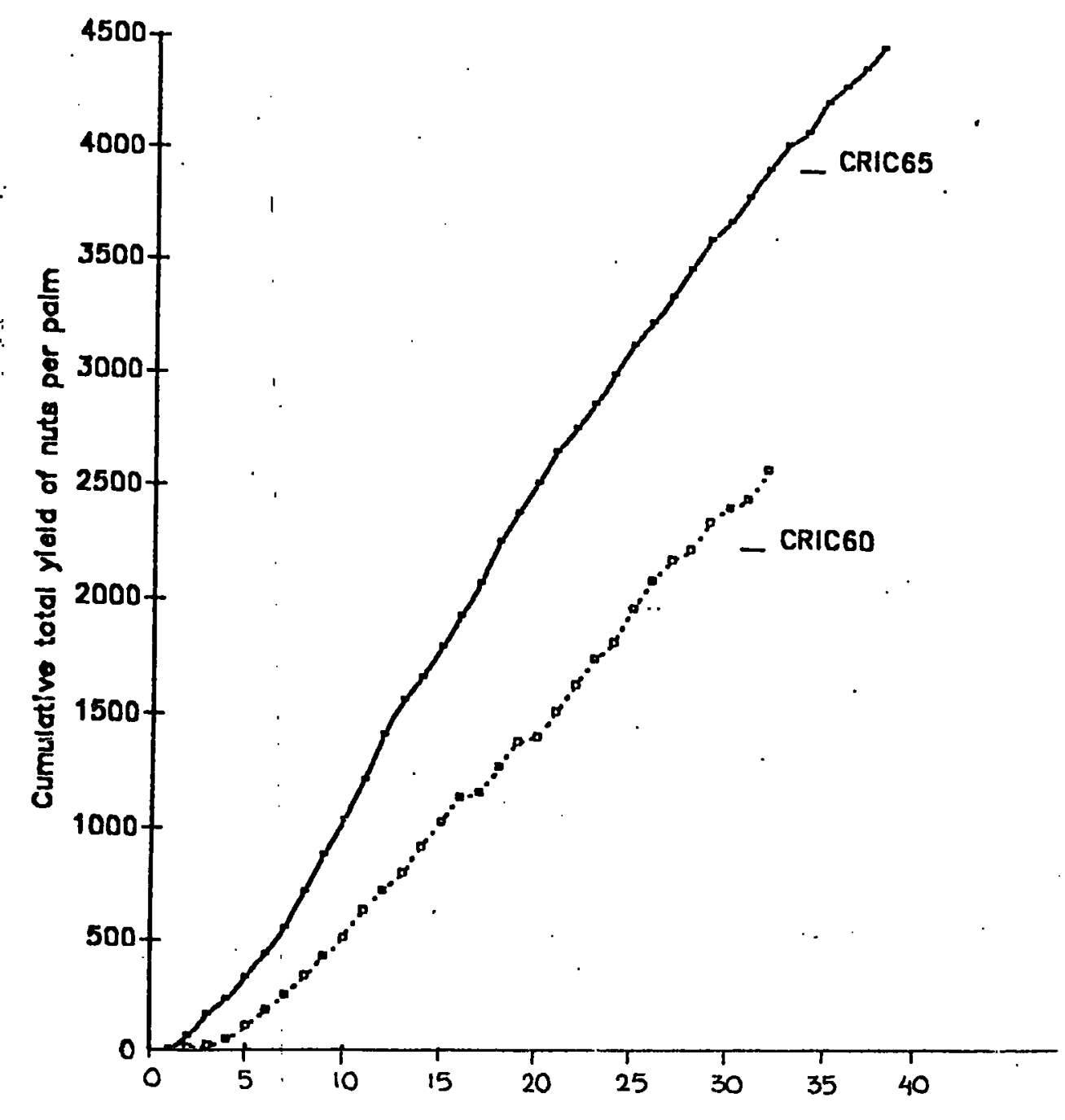

Figure 2 The cumulative yield of palms (CRIC60 and CRIC65) with time.

6 


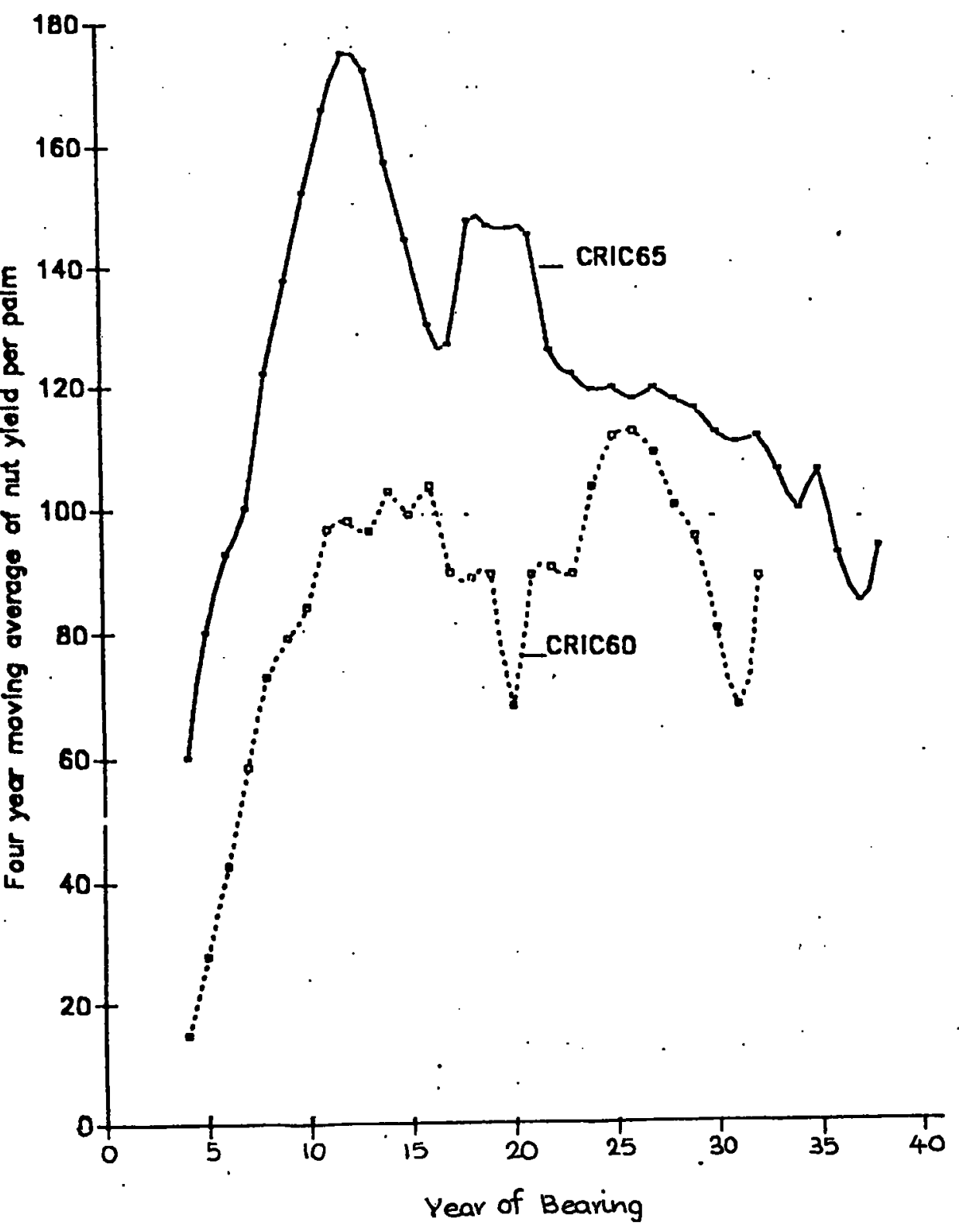

Figure 3 The four year moving average yield of CRIC60 and CRIC65 palms at the two locations 
This was with similar levels of applied fertilizer. Evidence confirms that the yield potential of D $\times$ T (CRIC65) is very much higher than that of CRIC60, under conditions of non-limiting soil water availability.

In CRIC60 and other tall coconuts replanting or underplanting is usually undertaken, when the plantation is over 60 years old and when the individual palm yield is reduced to about 15 nuts palm ${ }^{-1} \mathrm{yr}^{-1}$, due to senility. The oldest CRIC65 hybrid plantation is currently $\mathbf{4 3}$ years of age. It is not possible at this point in time to predict when senility would set-in and a yield decline would come about in the CRIC65: However, the cumulative yield up to the present time has been $51 \%$ higher in CRIC65 than in CRIC60 and this should compensate for any yield loss due to possible early senility. Considering the returns to investment, early high yield would be more profitable than a lower yield over an extended period of time. Under the circumstances, if coconut is to be grown under irrigation the dwarf $\mathrm{x}$ tall hybrid (CRIC65) has a greater potential productivity and hence should be the cultivar to be used.

These cultivars (CRIC60; CRIC65) have been so far evaluated only under the normal recommended levels of fertilizer. Being high yielding palms, they are likely to have a higher nutrient requirement, and perhaps a high nutrient use efficiency. The observed trend to yield decline in CRIC65 shown in Figure 3 could perhaps be related to inadequate nutrition to sustain the high productivity of the palm. Nutrient use efficiency of the palm is likely to be enhanced with the availability of an adequate amount of water in the root zone at all times. If supplementary irrigation is available, consideration would have to be given to the application of split doses of fertilizer, for greater efficiency and also perhaps high levels of fertilizer to meet the high level of nutrient removal due to higher yield. This is an area requiring further investigation.

\section{ACKNOWLEDGEMENTS}

The long term weather data were supplied by the Biometry Division of CRI. Thanks are due to Mr D T Mathes, Head, Biometry Division for his assistance in the analysis of data, to Mr N S Dias, Dr C R Panabokke, Dr (Mrs) C Jayasekara, Dr K S Jayasekara and Mr D T Mathes for their valuable comments on the manuscript and to Mrs I N Jayawardene for her assistance with word processing.

\section{REFERENCES}

Abeywardene V. (1968) Forecasting coconut crops using rainfall data. A preliminary study. Ceylon Coconut. Q. $19: 161-176$

Abeywardene V. (1971) Yield variation in coconut. Ceylon Coconut Q. 22: 97-103. CDA. 1990. Sri Lanka Coconut Statistics, Coconut Development Authority. 
Jayasekara, K. S. (1989) Report of the Soils and Plant Nutrition Division. In Annual Report of the Coconut Research Institute for 1989, 88-1.18.

Jayasekara, K. S.; Wahala, M. P. B., Jayasekara, C. and Peries, R. R. A. (1993) Water use of coconut (Cocos nucifera L.). Proc. 49th Annual Sessions SLAAS 1993.

Manthriratne, M.A.P.P. (1975) A comparative study of the growth, flowering and yield of (a) typica $x$ typica, (b) typica $x$ pumilla and (c) typica (OP) progeny. Paper presented at the Fourth Session of the FAO Working Party on coconut production, protection and processing, Kingston, Jamaica, October 1975.

Manthriratne, M.A.P.P. (1978) The choice of planting material and methods in a National Replanting Programme. Proceedings of the Seminar on. "Research and Development Programmes for Coconut Production", Colombo, March 1978. Coconut Research Institute.

Peries, R.R.A. (1992) Report of the Genetics and Plant Breeding Division. In Annual Report of the Coconut Research Institute for 1992, 47-97.

Rognon, F. and Delbose, G. (1990) Personal Communication. Institute de Recherches pour less Huiles et Oleagineux, Paris. 